\title{
Bird's Eye Lesions of Tomato Fruit Produced by Aerosol and Direct Application of Clavibacter michiganensis subsp. michiganensis
}

\author{
C. M. Medina-Mora, M. K. Hausbeck, and D. W. Fulbright, Department of Botany and Plant Pathology, \\ Michigan State University, East Lansing 48824-1312
}

\begin{abstract}
Medina-Mora, C. M., Hausbeck, M. K., and Fulbright, D. W. 2001. Bird's eye lesions of tomato fruit produced by aerosol and direct application of Clavibacter michiganensis subsp. michiganensis. Plant Dis. 85:88-91.

Development of the bird's eye fruit lesion of tomato was studied by inoculating flowers and the surface of young tomato fruit with strains of Clavibacter michiganensis subsp. michiganensis. Flowers were sprayed once or twice with $C$. michiganensis subsp. michiganensis at $10^{8} \mathrm{CFU} / \mathrm{ml}$. The maximum incidence $(80 \%)$ and severity (12 spots/fruit) of spotted fruit resulted when inoculum was sprayed twice, 3 days apart. Flowers were most susceptible to infection 2 days after anthesis. When a paintbrush was used to apply inoculum to the surface of small fruit, a large number of fruit spots ( $\leq 456$ spots/fruit) resulted. Even strains determined to be avirulent based on a tomato stem inoculation assay and a hypersensitive response on four-o'clock leaves (Mirabilis jalapa) were able to produce fruit spots, although at a reduced level. The inoculation methods developed in this study can provide opportunities to observe subtle host-pathogen interactions between $C$. michiganensis subsp. michiganensis strains and tomato and to help formulate methods to quantify infection.
\end{abstract}

Additional keywords: avirulence, bacterial canker, rep-PCR

Bacterial canker of tomato, caused by Clavibacter michiganensis subsp. michiganensis, is a concern for tomato growers because the disease can drastically reduce tomato yield and quality $(4,11,13)$. Symptoms of disease caused by the systemic, gram-positive pathogen include necrosis of the leaf margin, stunting, wilting, vascular discoloration, and plant death (17). Disease symptoms on the fruit include small, raised, superficial necrotic spots surrounded by white halos. These lesions, referred to as bird's eye lesions $(3,17)$, can cause economic losses in fresh market tomatoes due to reduced fruit quality (3).

Studies in which flowers and fruit were inoculated with bacterial pathogens have demonstrated the importance of natural openings (5,7-9) and injured tissue (16) in fruit infection. Bacterial speck lesions, caused by Pseudomonas syringae pv. tomato, on tomato fruit developed following the external inoculation of flowers during and after anthesis $(7,8)$. Watermelon fruit lesions caused by Acidovorax avenae subsp. citrulli were reduced when infection

Corresponding author: D. W. Fulbright

E-mail address: fulbrig1@pilot.msu.edu

This study was supported by funding from the Michigan Agricultural Experiment Station.

Accepted for publication 25 September 2000.

Publication no. D-2000-1030-02R

(C) 2001 The American Phytopathological Society courts on the fruit were covered with wax (9). Pepper fruit, wounded by sandblasting and inoculated with Xanthomonas campestris pv. vesicatoria, showed an increased number of spots per fruit when compared to nonwounded, inoculated fruit (16). A study by Ehrig and Griesbach (5) reported that bird's eye lesions of tomato are the result of external infection rather than internal systemic infection. However, their report did not describe the role of inoculum in relation to flower and fruit development.

Prevention of bacterial canker includes the use of certified seed, healthy transplants, disinfested greenhouse materials and facilities, and rotation away from tomatoes for at least 2 years (12). Although the application of bactericides to seedlings in the greenhouse was shown to reduce yield losses due to $C$. michiganensis subsp. michiganensis infection (13), a management program to reduce incidence of fruit spotting has not been developed. Therefore, to control bird's eye lesions, a better understanding of the infection process is required. The objective of this study was to determine the earliest stage of flower or fruit development that is susceptible to infection by $C$. michiganensis subsp. michiganensis in order to devise strategies that may reduce fruit spotting in the field.

\section{MATERIALS AND METHODS}

Inoculum preparation and flower inoculation. The $C$. michiganensis subsp. michiganensis strains used in each experi- ment represent distinct polymerase chain reaction (BOX-PCR) fingerprint types designated as type A (Cmm 292) or type B (Cmm 68) (15). Cmm 68 and Cmm 292 were isolated from fruit lesions from Ohio (in 1987) and Michigan (in 1993) fields, respectively. Pathogenicity tests on tomato plants and the hypersensitive response (HR) on four-o'clock leaves (Mirabilis jalapa; 10) indicated that both strains were virulent (15). Both strains were stored in glycerol stock cultures $(1 \mathrm{ml}$ of broth culture per $0.5 \mathrm{ml}$ of $40 \%$ glycerol) kept at $-80^{\circ} \mathrm{C}$ and recovered at the start of each experiment by streaking onto nutrient broth yeast extract agar (NBY) plates (6).

Inoculum was prepared by inoculating NBY broth with $5 \mathrm{ml}$ of a 48-h-old culture in NBY broth of either bacterial strain and placing it on a shaker at $200 \mathrm{rpm}$ at room temperature for $48 \mathrm{~h}$. Using NBY broth as the dissolvent, a serial dilution of each culture was conducted and spectrophotometer readings were performed at 600 $\mathrm{nm}$ to each dilution series. The serial dilution that corresponded to $50 \%$ transmittance was used as a reference to calculate the volume of the original culture necessary to prepare a diluted culture of approximately $10^{8} \mathrm{CFU} / \mathrm{ml}$. The diluted culture was centrifuged in a desktop clinical centrifuge (IEC Clinical Centrifuge, Needham Hts., MA) for $15 \mathrm{~min}$ at maximum speed and the pellet was suspended in sterile distilled water, recentrifuged, and the cells resuspended in $100 \mathrm{ml}$ of sterile distilled water. The final concentration of the inoculum used for all tomato flowers inoculations ranged from $3 \times 10^{7}$ to $3 \times 10^{8}$ $\mathrm{CFU} / \mathrm{ml}$. Prior to flower inoculation, each bacterial suspension prepared was tested for its ability to induce an HR, a condition assumed to correlate with virulence of the pathogen (15).

Two tomato transplants of the susceptible processing cultivar Heinz 8704 (H. J Heinz Co., Stockton, CA) were set in 31$\mathrm{cm}$-diameter clay pots filled with commercially prepared potting media (Baccto; Michigan Peat Co., Houston, TX). Tomato plants were grown in the greenhouse for approximately 8 weeks under sodium vapor lights with a photoperiod of $18 \mathrm{~h}$. Greenhouse temperatures ranged from 25 to $30^{\circ} \mathrm{C}$ (day) and 18 to $22^{\circ} \mathrm{C}$ (night). Tomato plants were fertilized twice each week with a 200-ppm solution of Peters 20-20-20 (Scotts, Allentown, PA). 
Inoculations were performed by applying approximately $0.7 \mathrm{ml}$ of the washed $C$. michiganensis subsp. michiganensis suspension per flower using an air-pressurized sprayer (Preval, Precision Valve Co., Yonkers, NY); sterile distilled water was used as a control. A small circle, approximately $25 \mathrm{~mm}$ in diameter and large enough to cover a single flower with a wide open corolla, was cut in the bottom of a clear plastic cup $(60 \mathrm{ml})$. Individual flowers were inserted into the bottom of the cup before applying the inoculum or sterile distilled water, to direct the fine mist toward each flower and to limit the amount of aerosol landing on adjacent flowers and tissues.

Inoculation of flowers and bagging. The first treatment consisted of a single inoculation of two to four flowers per inflorescence when the corollas were fully expanded. The second treatment consisted of two inoculations, the first when the corollas were fully expanded and the second 3 days later. The third and fourth treatments were inoculated in the same manner as treatments 1 and 2 above and, following each inoculation, individual clusters of flowers were covered with clear plastic bags ( 18 by 18 by $6 \mathrm{~cm}$ ) for 16 to $18 \mathrm{~h}$. For every treatment mentioned above, sterile distilled water was sprayed as a control. The experiment was conducted twice, and the repetitions are hereafter referred to as experiments 1 and 2 .

An average of 66 and 30 flowers were used for experiments 1 and 2, respectively. C. michiganensis subsp. michiganensis strains (Cmm 68 and Cmm 292) were used as inocula in experiment 1 and 2, respectively. Three weeks after the second inoculation for treatments 3 and 4, all fruit were inspected for bird's eye lesions. The number of fruit infected and the number of spots per fruit were recorded. The average number of spots per fruit for each treatment from both experiments were analyzed by using Kruskal-Wallis analysis of variance (ANOVA) by ranks $(P<0.05)$ and differences between treatments were identified using pairwise multiple comparison by Dunn's method (SigmaStat, SPSS, Inc., Chicago, IL). These methods were used because data were not normally distributed and there was no appropriate transformation (14).

A subsample of fruit spots was randomly sampled to confirm that developing lesions were caused by the specific inoculum sprayed. Fruit spots were excised using a sterile scalpel and placed in a droplet of sterile distilled water for $5 \mathrm{~s}$. Each droplet was streaked onto NBY plates and incubated for $96 \mathrm{~h}$ at room temperature. After repeated streaking to obtain pure cultures, the colonies resembling $C$. michiganensis subsp. michiganensis were subjected to repetitive sequence-based polymerase chain reaction (rep-PCR) fingerprinting (15) to demonstrate that the BOX-PCR genotype was the same as that of the inoculum used in each experiment.

Inoculation of fruit. Bacterial suspensions were prepared as described above and directly applied to the entire surface of young green fruits 10 to $15 \mathrm{~mm}$ in diameter using a \#2, artist-style, camel's hair paintbrush. Ten $C$. michiganensis subsp. michiganensis strains were selected based on their BOX-PCR fingerprint type and virulence rating (15). C. michiganensis subsp. michiganensis strains 299 (type A), 68R (type B), 68 (type B), and 285 (type D) are classified as virulent; T33 (type A), 236 (type C), and 56 (type C) represent strains with intermediate virulence; and 363 (type A), 208 (type A), and 133 (type A) are classified as avirulent (15). Each bacterial suspension was applied to a maximum of five fruit, with only one bacterial strain per fruit. The suspensions were simultaneously tested for HR on fouro'clock leaves. Five fruit were brushed with sterile distilled water as a control. This experiment was conducted three times. Four weeks after fruit inoculation, the number of infected and noninfected fruit and the number of spots per fruit were recorded. The average number of spots per fruit for each strain was statistically analyzed as described above. Five fruit spots per fruit, representing each bacterial strain used in the study, were arbitrarily selected and excised as described above. Pure culture colonies resembling $C$. michiganensis subsp. michiganensis were subjected to rep-PCR fingerprinting to confirm the BOX-PCR genotype of the inocula.

Flower development stage in relation to fruit spots. A bacterial suspension (approximately $10^{8} \mathrm{CFU} / \mathrm{ml}$ ) of strain $\mathrm{Cmm} 68$ was prepared and applied to five flower developmental stages as defined using anthesis (pollen maturity) as the reference point. Each flower at the desired developmental stage was inoculated once and its inflorescence was covered with a clear plastic bag ( 18 by 18 by $6 \mathrm{~cm}$ ) for 16 to $18 \mathrm{~h}$. Bhadula and Sawhney (1) established that tomato calyces 11.0 to $12.0 \mathrm{~mm}$ in length with an open corolla corresponded to flowers at anthesis. Therefore, the first stage of flower development, considered to be about 5 days prior to anthesis, consisted of buds with closed calyces approximately 11 to $12 \mathrm{~mm}$ in length. The flower developmental stages inoculated in this experiment were five $(-5)$ and three $(-3)$ days preanthesis, anthesis (0), two $(+2)$ and four $(+4)$ days postanthesis, corresponding to closed calyx, open calyx, partially open corolla, fully open corolla, and half-closed corolla, respectively (Fig. 1). For each flower developmental stage, sterile distilled water was used as a control. The experiment was conducted three times with an average of 57, 65, and 66 flowers available for each experiment. When the youngest fruit reached $27 \mathrm{~mm}$ in diameter, the number of infected and noninfected fruit and the number of spots per fruit were recorded. The average number of spots per fruit for each experiment was statistically analyzed as previously mentioned. Colonies resembling $C$. michiganensis subsp. michiganensis were isolated from fruit spots and subjected to rep-PCR fingerprinting.

\section{RESULTS}

Inoculation of flowers. At 6 to 8 days after inoculation of flowers with open corollas, white lesions appeared on fruit that were 10 to $12 \mathrm{~mm}$ in diameter. At 3 to 5 days after the white lesions appeared, they

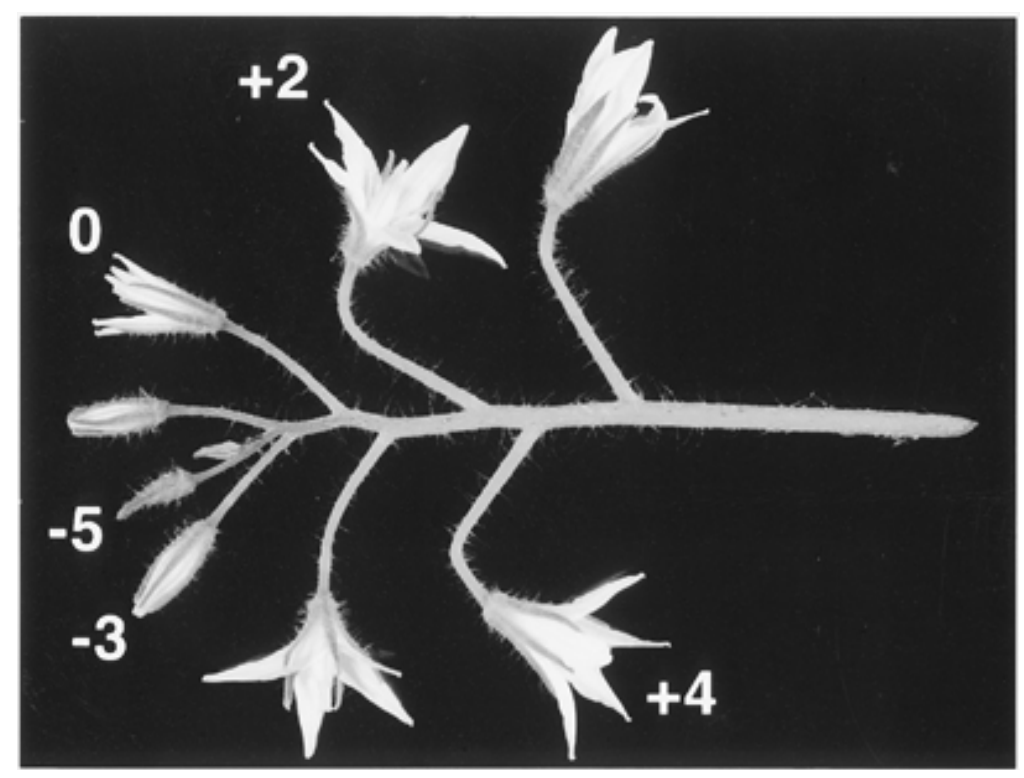

Fig. 1. The five developmental stages of tomato flowers inoculated with Clavibacter michiganensis subsp. michiganensis to determine the susceptibility of flowers to infection: $-5=5$ days preanthesis (closed calyx), $-3=3$ days preanthesis (open calyx), $0=$ anthesis (partially open corolla), $+2=2$ days postanthesis (fully open corolla), and $+4=4$ days postanthesis (half-closed corolla). 
became necrotic (Fig. 2), resembling the typical bird's eye lesion. Some fruit spots were atypical of bird's eye lesions in that they developed necrosis but lacked a white halo. All lesions were circular, approximately $2 \mathrm{~mm}$ in diameter, and superficial, with a raised, blister-like appearance. RepPCR assays confirmed that bacteria isolated from the fruit spots were the same $C$. michiganensis subsp. michiganensis strains used as inoculum.

The percent of fruit with lesions and the number of lesions per fruit were a function primarily of the number of inoculations each flower received (Table 1). Fruit developing from flowers that were inoculated twice had the highest percent of fruit with lesions $(\geq 53 \%)$ and the highest number of spots $(\geq 7)$ per fruit. When flowers were inoculated once, a maximum of $32 \%$ of fruit exhibited an average of 0.2 to 2 spots per fruit. Bagging flowers to maintain high humidity following inoculation did not increase the number of spots per fruit; however, the incidence of symptomatic fruit increased in the $1 \times$-inoculated treatment with bagging (Table 1). Similar results were observed with all strains tested. No fruit spots developed on control flowers sprayed with sterile water.

Inoculation of fruit. Fruit spotting occurred after green fruit were inoculated using a paintbrush dipped in C. michiganensis subsp. michiganensis (Table 2). Strains determined to be virulent in previous studies (16) and reacting positively in the HR assay in this study caused spots on 80 to $100 \%$ of the inoculated fruit. Strains classified as intermediate in virulence and causing positive reactions in $\mathrm{HR}$ assays resulted in 67 to $100 \%$ of the inoculated fruit developing spots. Strains determined to be avirulent in previous studies and producing negative reactions in HR assays resulted in 60 to $100 \%$ of the inoculated fruit developing spots. No spotted fruit resulted when the surfaces of fruit were brushed with sterile water. Generally, the number of spots per fruit was higher on fruit inoculated with virulent and intermediate strains than on fruit inoculated with avirulent strains. No significant fruit abortion occurred as a result of brushing the young fruit with the paintbrush (data not shown).

Flower development stage in relation to fruit spot development. A minimum of $15 \%$ of the fruit produced from flowers inoculated 2 or 4 days after anthesis developed characteristic bird's eye lesions (Table 3). Inoculation at these times also

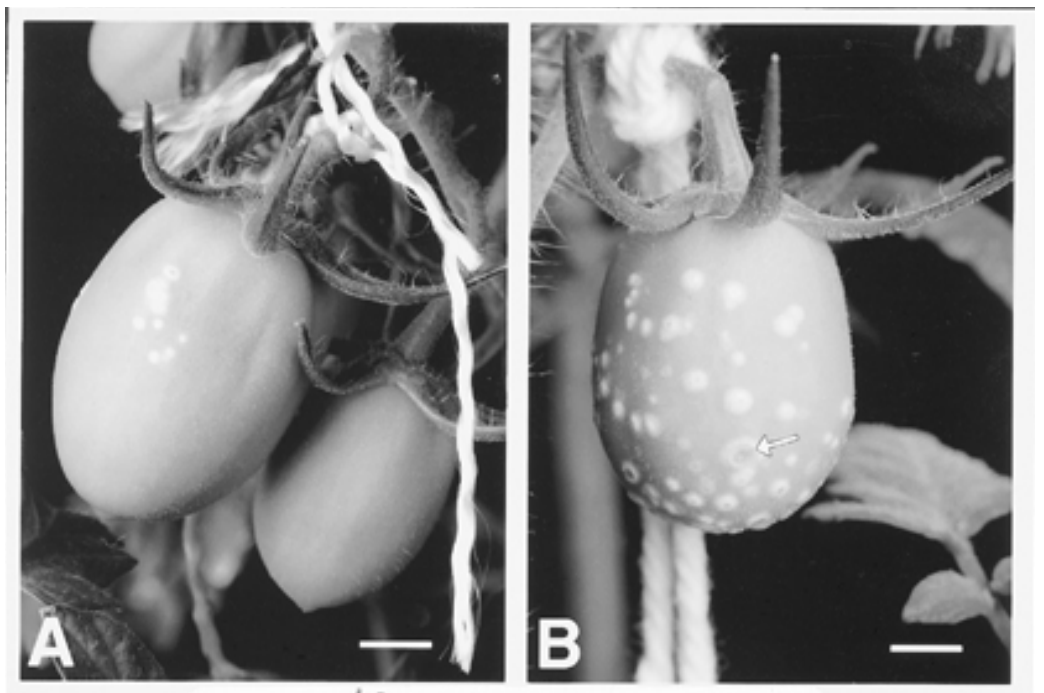

Fig. 2. Tomato fruit showing bird's eye lesions A, 14 days after Clavibacter michiganensis subsp. michiganensis inoculum was sprayed on stage 0 flowers and $\mathbf{B}, 10$ days after inoculum was applied using an artist's paintbrush to the surface of young green fruit (13 $\mathrm{mm}$ in diameter). Arrow indicates a fully developed bird's eye lesion, where dark necrotic tissue is surrounded by a white halo. Scale bars $=1 \mathrm{~cm}$.

Table 2. Fruit spot development after brushing Clavibacter michiganensis subsp. michiganensis on the surface of young tomato fruit ${ }^{\mathrm{x}}$

\begin{tabular}{|c|c|c|c|c|c|c|}
\hline \multirow[b]{2}{*}{ Virulence, strain $^{z}$} & \multicolumn{3}{|c|}{ Fruit with lesions (\%) } & \multicolumn{3}{|c|}{ No. spots/fruit ${ }^{y}$} \\
\hline & Exp. 1 & Exp. 2 & Exp. 3 & Exp. 1 & Exp. 2 & Exp. 3 \\
\hline \multicolumn{7}{|l|}{ Virulent } \\
\hline Cmm 299 & 100 & 100 & 100 & $60 \mathrm{a}$ & $132 \mathrm{a}$ & $212 \mathrm{a}$ \\
\hline Cmm 285 & $\ldots$ & 100 & 100 & $\ldots$ & $225 \mathrm{a}$ & $141 \mathrm{a}$ \\
\hline Cmm 68R & 100 & 100 & 100 & $66 \mathrm{a}$ & $326 a$ & $210 \mathrm{a}$ \\
\hline Cmm 68 & $\ldots$ & 100 & 80 & $\ldots$ & $456 \mathrm{a}$ & $178 \mathrm{a}$ \\
\hline \multicolumn{7}{|l|}{ Intermediate } \\
\hline Cmm T33 & 67 & 100 & 100 & $45 \mathrm{a}$ & $178 \mathrm{a}$ & $241 \mathrm{a}$ \\
\hline Cmm 236 & 100 & $\ldots$ & 100 & $109 \mathrm{a}$ & $\ldots$ & $148 \mathrm{a}$ \\
\hline Cmm 56 & 100 & $\ldots$ & 100 & $24 \mathrm{a}$ & $\ldots$ & 389 a \\
\hline \multicolumn{7}{|l|}{ Avirulent } \\
\hline Cmm 363 & $\ldots$ & 100 & 60 & $\ldots$ & $24 \mathrm{a}$ & $32 \mathrm{~b}$ \\
\hline Cmm 208 & 80 & 100 & 100 & $15 \mathrm{a}$ & $40 \mathrm{a}$ & $179 a$ \\
\hline Cmm 133 & 75 & $\ldots$ & 60 & $27 \mathrm{a}$ & $\ldots$ & $56 a$ \\
\hline
\end{tabular}

${ }^{\mathrm{x}}$ Five green fruit were included in experiments 1 and 3 , and three fruit in experiment $2 ; \ldots$ indicates strain not included in experiment.

y Statistical analysis using Kruskal-Wallis analysis of variance by ranks and pairwise multiple comparison Dunn's method. Values for each experiment were not significant at $P \leq 0.05$. $n=35,21$, and 40 for experiment 1,2 , and 3 , respectively.

z Virulence rating as described by Louws et al. (15): Virulent = producing canker and wilt; Intermediate = producing canker only; and Avirulent = producing no symptoms by stem inoculation assays.

Table 1. Fruit spot development after inoculating open corollas of flowers with strains of Clavibacter michiganensis subsp. michiganensis

\begin{tabular}{|c|c|c|c|c|c|c|c|c|c|}
\hline \multicolumn{2}{|l|}{ Treatment } & \multicolumn{2}{|c|}{ No. flowers inoculated ${ }^{x}$} & \multicolumn{2}{|c|}{ Total fruit } & \multicolumn{2}{|c|}{ Fruit with lesions (\%) } & \multicolumn{2}{|c|}{ No. spots/fruit ${ }^{y}$} \\
\hline Inoculation & Bag $^{z}$ & Exp. 1 & Exp. 2 & Exp. 1 & Exp. 2 & Exp. 1 & Exp. 2 & Exp. 1 & Exp. 2 \\
\hline $1 \times$ & - & 31 & 81 & 29 & 46 & 14 & 9 & $0.4 \mathrm{a}$ & $0.2 \mathrm{a}$ \\
\hline $2 x$ & - & 31 & 128 & 30 & 61 & 80 & 70 & $12 \mathrm{~b}$ & $7 \mathrm{~b}$ \\
\hline $1 \times$ & + & 36 & 64 & 31 & 29 & 32 & 28 & $2 \mathrm{a}$ & $1 \mathrm{a}$ \\
\hline $2 x$ & + & 29 & 122 & 23 & 72 & 78 & 53 & $7 \mathrm{~b}$ & $7 \mathrm{~b}$ \\
\hline
\end{tabular}

${ }^{\mathrm{x}}$ Flowers with open corollas sprayed with C. michiganensis subsp. michiganensis strains Cmm 68 and Cmm 292 for experiments 1 and 2 , respectively.

${ }^{y}$ Statistical analysis using Kruskal-Wallis analysis of variance by ranks and pairwise multiple comparison Dunn's method. Values for both test were significant at $P \leq 0.05$.

${ }^{\mathrm{z}}$ Incubation of $C$. michiganensis subsp. michiganensis on open corollas after covering individual inflorescences with clear plastic bags for 16 to $18 \mathrm{~h}$ after inoculation. 
Table 3. Fruit spotting after inoculating flowers at various developmental stages with Clavibacter michiganensis subsp. michiganensis

\begin{tabular}{|c|c|c|c|c|c|c|c|c|c|}
\hline \multirow[b]{2}{*}{ Flower stage ${ }^{z}$} & \multicolumn{3}{|c|}{ Total no. fruit } & \multicolumn{3}{|c|}{ Fruit with lesions (\%) } & \multicolumn{3}{|c|}{ Average no. spots/fruit ${ }^{y}$} \\
\hline & Exp. 1 & Exp. 2 & Exp. 3 & Exp. 1 & Exp. 2 & Exp. 3 & Exp. 1 & Exp. 2 & Exp. 3 \\
\hline-5 & 30 & 12 & 22 & 0 & 0 & 0 & $0.0 \mathrm{a}$ & $0.0 \mathrm{a}$ & $0.0 \mathrm{a}$ \\
\hline-3 & 23 & 14 & 20 & 0 & 0 & 5 & $0.0 \mathrm{a}$ & $0.0 \mathrm{a}$ & $0.05 \mathrm{a}$ \\
\hline 0 & 48 & 29 & 16 & 6 & 0 & 0 & $0.1 \mathrm{a}$ & $0.0 \mathrm{a}$ & $0.0 \mathrm{a}$ \\
\hline+2 & 54 & 47 & 57 & 30 & 15 & 42 & $1.7 \mathrm{~b}$ & $0.8 \mathrm{a}$ & $2.8 \mathrm{~b}$ \\
\hline+4 & 46 & 59 & 35 & 30 & 20 & 37 & $0.4 \mathrm{~b}$ & $0.5 \mathrm{a}$ & $1.9 \mathrm{~b}$ \\
\hline
\end{tabular}

y Statistical analysis using Kruskal-Wallis analysis of variance by ranks and pairwise multiple comparison Dunn's method.

${ }^{\mathrm{z}}$ Flower developmental stages were five $(-5)$ and three $(-3)$ days preanthesis, anthesis $(0)$, two $(+2)$ and four $(+4)$ days postanthesis, corresponding to closed calyx, open calyx, partially open corolla, fully open corolla, and half-closed corolla, respectively.

\section{DISCUSSION}

This is the first report on the development of bird's eye tomato fruit lesions following inoculation of flowers or fruit with $C$. michiganensis subsp. michiganensis. Two greenhouse protocols, one where the flowers were sprayed with the pathogen and the other where the pathogen was placed on young fruit with a paintbrush, were developed in this study to obtain fruit lesions.

In the first protocol, spraying tomato flowers twice with a bacterial aerosol produced a higher percentage of fruit with lesions as well as a higher number of spots per fruit than a single inoculation, whether or not flowers were bagged after inoculation. When inoculating once, bagging the flowers and thereby keeping humidity high resulted in an increased number of spotted fruit.

Significant fruit spotting did not occur unless bacteria were applied after anthesis, suggesting that the bacterial population on the flower must be relatively high at the latter stages of the flower development in order to cause significant fruit spotting. This could be one reason why the bird's eye lesion is the most inconsistent of the bacterial canker symptoms observed during field epidemics (M. K. Hausbeck and D. W. Fulbright, personal observation). Although the application of $10^{8} \mathrm{CFU} / \mathrm{ml}$ of $C$. michiganensis subsp. michiganensis to preanthesis and anthesis flowers should have been adequate to establish epiphytic populations that could serve as inoculum to the developing ovaries, perhaps petal abscission reduced the population and bacterial cells were unable to colonize the ovary tissue. Perhaps, in the field, where rain, wind, and splashing water are likely to enhance infection and epiphytic bacterial populations and facilitate infection, preanthesis and anthesis flower infection may occur more readily than in our study.

A few spotted fruit developed from flowers inoculated before or during anthesis. If a large pathogen population was present a few days before the optimum infection stage, this population might still be viable at the optimum time for infection (3 to 5 days later). However, this possibility was not evaluated. Also, bagging of inoculated flowers may have provided the high relative humidity necessary to sustain pathogen populations long enough for inoculations before and during anthesis to result in infection.
In the second protocol, a large number of fruit spots resulted from external inoculation of young green fruit using a paintbrush. In a similar experiment, Volcani et al. (18) used a brush and carborundum to achieve similar results when applying $C$. michiganensis subsp. michiganensis to pepper. In our study, physical abrasion was not required for fruit spot production; the paintbrush alone may have produced the needed abrasive action or the brush may have efficiently delivered the pathogen to the natural openings in the epidermis of the tomato fruit $(2,7)$. It was interesting to note that strains not having the ability to produce wilt, canker, and marginal necrosis of leaves in previous pathogenicity assays (16), and verified as negative in HR assays, caused bird's eye lesions, suggesting that we do not have a good understanding of pathogenesis in this pathosystem.

This study supports our general understanding that bacterial fruit spots result from inoculation through stomata or other natural openings on ovaries or young fruit $(2,7)$. Reducing the pathogen populations at the critical stages of postanthesis and early fruit development through copper applications may decrease incidence of spotted fruit. Management strategies utilizing biological controls or genetically engineered hosts could also benefit from knowledge of the development of fruit spots. Effective biocontrol agents might specifically colonize flowers and ovaries, thereby reducing the pathogen populations that might cause fruit lesions. Genetically modified tomatoes could also deliver pathogen-inhibiting compounds in targeted cells, such as trichomes on the ovary.

\section{ACKNOWLEDGMENTS}

We thank J. Rogers for statistical assistance, I. Widders for providing technical advice, and J. Bell for providing information regarding the virulence characterization of the strains used in this study.

\section{LITERATURE CITED}

1. Bhadula, S. K., and Sawhney, V. K. 1987. Esterase activity and isozymes during the ontogeny of stamens of male fertile Lycopersicon esculentum Mill., a male sterile stamenless-2 mutant and the low temperaturereverted mutant. Plant Sci. 52:187-194.

2. Blanke, M. M. 1986. Comparative SEM study of stomata on developing quince, apple, grape, and tomato fruit. Angew. Bot. 60:209-214.

3. Bryan, M. K. 1930. Studies on bacterial canker of tomato. J. Agric. Res. 41:825-850.
4. Chang, R. J., Ries, S. M., and Pataky, J. K 1992. Reductions in yield of processing tomatoes and incidence of bacterial canker. Plant Dis. 76:805-809.

5. Ehrig, F., and Griesbach, E. 1985. Development of bird eye spots on tomato fruits-Investigations by scanning electron microscopy. Arch. Phytopathol. Pflanzenschutz 21:419-423.

6. Fatmi, M., and Schaad, N. W. 1988. Semiselective agar medium isolation of Clavibacter michiganensis subsp. michiganensis from tomato seed. Phytopathology 78:121-126.

7. Getz, S., Fulbright, D. W., and Stephens, C. T. 1983. Scanning electron microscopy of infection sites and lesion development on tomato fruit infected with Pseudomonas syringae pv. tomato. Phytopathology 73:39-43.

8. Getz, S., Stephens, C. T., and Fulbright, D. W. 1983. Influence of developmental stage on susceptibility of tomato fruit to Pseudomonas syringae pv. tomato. Phytopathology 73:36-38.

9. Giles Fankle, W., Hopkins, D. L., and Stall, R. E. 1993. Ingress of the watermelon fruit blotch bacterium into fruit. Plant Dis. 77:1090-1092.

10. Gitaitis, R. 1990. Induction of a hypersensitive-like reaction in four o'clock by Clavibacter michiganensis subsp. michiganensis. Plant Dis. 74:58-60.

11. Gitaitis, R. 1991. Bacterial canker. Pages 2526 in: Compendium of Tomato Diseases. 2nd ed. J. B. Jones, J. P. Jones, R. E. Stall, and T. A. Zitter, eds. American Phytopathological Society Press, St. Paul, MN.

12. Gleason, M. L., Gitaitis, R. D., and Ricker, M. D. 1993. Recent progress in understanding and controlling bacterial canker of tomato in eastern North America. Plant Dis. 77:1069-1076.

13. Hausbeck, M., Bell, J., Medina-Mora, C., Podolsky, R., and Fulbright, D. W. 2000. Effect of bactericides on population sizes and spread of Clavibacter michiganensis subsp. michiganensis on tomatoes in the greenhouse and on disease development and crop yield in the field. Phytopathology 90:38-44.

14. Hoshmand, A. R. 1988. Statistical Methods for Agricultural Sciences. Timber Press, Portland, OR.

15. Louws, F. J., Bell, J., Medina-Mora, C. M., Smart, C. D., Opgenorth, D., Ishimaru, C.A., Hausbeck, M. K., de Bruijn, F. J., and Fulbright, D. W. 1998. Rep-PCR-mediated genomic fingerprinting: A rapid and effective method to identify Clavibacter michiganensis. Phytopathology 88:862-868.

16. Pohronezny, K., Hewitt, M., and Infante, J. 1993. Susceptibility of pepper fruit to infection by Xanthomonas campetris pv. vesicatoria. Can. J. Plant Pathol. 15:107-108.

17. Strider, D. L. 1969. Bacterial canker of tomato caused by Corynebacterium michiganense: A literature review and bibliography. N. C. Exp. Stn. Tech. Bull. 193:110.

18. Volcani, Z., Zutra, D., and Cohn, R. 1970. A new leaf and fruit spot disease of pepper caused by Corynebacterium michiganense. Plant Dis. Rep. 54:804-806. 